\title{
SET UP OF ARTICULATED JOINT FOR FOLDING TRANSMISSION CHAIN USED ON LABOUR-AID MACHINE FOR BLACK TOBACCO LEAVE HARVESTING
}

\author{
Simone Pascuzzi ${ }^{1}$, Artur Przywara ${ }^{2}$, Alexandros Sotirios Anifantis ${ }^{1}$, Artur Kraszkiewicz ${ }^{2}$, Pawel Sobczak ${ }^{2}$ \\ ${ }^{1}$ University of Bari Aldo Moro, Italy; ${ }^{2}$ University of Life Sciences in Lublin, Poland \\ simone.pascuzzi@uniba.it,artur.przywara@up.lublin.pl, alexandrossotirios.anifantis@uniba.it, \\ artur.kraszkiewicz@up.lublin.pl,pawel.sobczak@up.lublin.pl
}

\begin{abstract}
Numberless mechanical applications require articulated roller chains for the motion transmission. As known, the articulated roller chains consist of couplings among internal and external links and the only possible movement is the reciprocal rotations among the turning couples in the plane of the chain. An articulated joint has been set up that makes also possible folding of articulated roller chains in planes different from the operative ones. Practically, this articulated joint is given by the replacement of two stretches of consecutive links, positioned symmetrically on opposite sides, with chains formed by closed rings. Therefore, the continuity on each stretch is given by the connection of the ends of two ordinary chains to the loose links of the articulated chain. The articulated joint has been patented in Italy. We have mounted an articulated roller chain fitted with the set up articulated joint inside a labour-aid machine for harvesting of tobacco leaves, in which the aforesaid device makes it possible the reduction of the size of the machine itself during the road transfers. We have tested the performance of this machine during tobacco leave harvesting in an Italian farm cultivating Virginia Bright tobacco.
\end{abstract}

Keywords: transmission efficiency, contact mechanics, articulated roller transmission, articulated joint, tobacco harvesting.

\section{Introduction}

Articulated chains are used for the motion transmission inside numerous mechanical applications and the most common is certainly the roller articulated chain [1-3]. These chains are employed because of their high power transmission efficiency, which is regularly greater than $95 \%$ [4-7]. The articulated roller chain consists of a train of external and internal links arranged alternately; the external link consists of an external lateral plate with two solid pins and a second plate to be applied to the free ends of the two pins [8]. The internal link is made up of an internal lateral plate with two bushes, on which two rollers rotate freely, and a second internal plate (Fig.1). The couplings between the internal and external links are of the turning type and the only movement allowed is reciprocal rotation in the plane of the chain (in the following operating plan) [9].

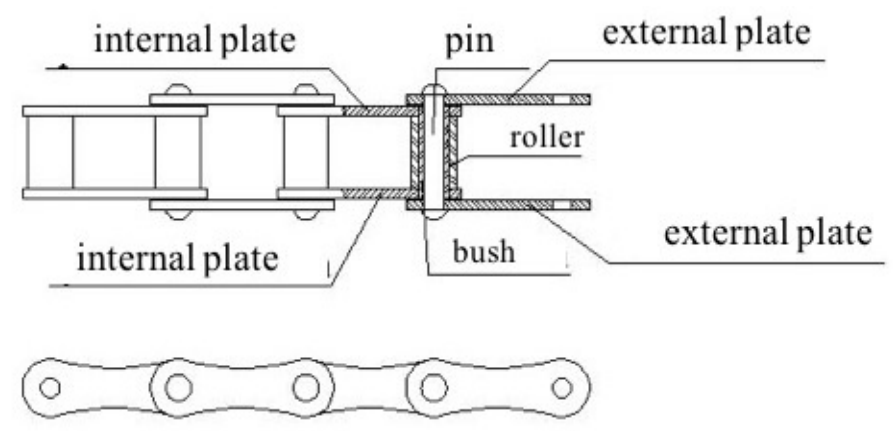

Fig. 1. Main components of an articulated roller chain

A low cost articulated joint that allows folding of this type of articulated roller chains in planes different from the operative one has been developed. This articulated joint can be employed in any articulated roller transmission and its main characteristics are reported in the present paper. As an example,the set up articulated joint was mounted on a labour-aid machine for harvesting of tobacco leaves, so as to allow the reduction of the size of the machine during road transfers. As known, for Virginia Bright tobacco more than $50 \%$ of manpower hours are still required by the leaf harvest and care phase [10-12]. The integral mechanization of the harvesting phase, with specific harvesting machines currently practiced in the United States, is still partly employed in Italy [13-15]. The operations of harvesting tobacco leaves, if carried out by hand, require a strong labour effort with very significant costs and then in the sector you resort to mechanized solutions, especially through specially equipped labour-aid machines $[16 ; 17]$. 


\section{Materials and methods}

The set up articulate joint

As known, the transmission of motion between two toothed wheels through an articulated roller chain takes place by coupling the teeth of the wheels with the openings of the chain links. The number of teeth $z$ and the primitive radius $R$ of the wheel (the radius along which the centers of the pins of the chain are located) are linked to the pitch $p$ of the chain by the relation $[1 ; 3]$ :

$$
p=2 R \sin \frac{\pi}{2} \text {. }
$$

Furthermore, if the articulated chain transmits motion between two toothed wheels $\left(R_{1}, z_{1}, R_{2}, z_{2}\right)$, having angular speeds respectively $\omega_{1}$ and $\omega_{2}$, the average transmission ratio $\tau_{m}$ is:

$$
\tau_{m}=\frac{\omega_{1}}{\omega_{2}}=\frac{z_{2}}{z_{1}}
$$

Where $\omega_{1}$ is the angular velocity of the driving toothed wheel and the total length $L$ of the chain, indicating with $i$ the distance between the axles of the two wheels can be obtained from the following rough relationship $[4 ; 18]$ :

$$
\frac{L}{p}=\frac{2 i}{p}+\frac{z_{1}+z_{2}}{2}+\frac{\left(z_{2}-z_{1}\right)^{2}}{4 \pi^{2}(i / p)}
$$

According to the aforesaid structural conformation, this type of articulated chains can undergo foldings due to mutual rotations of the links only in the operating plane; whereas it is not possible to bend or flex the links in planes other than this one.

The set up articulate joint is made by replacing, in an articulated chain of length $\mathrm{L}$, two stretches of links having the same size $L_{n}$, positioned symmetrically on opposite sides, with chains formed by closed rings (ordinary chains), keepingthe initial length $L$ (Figure 2).

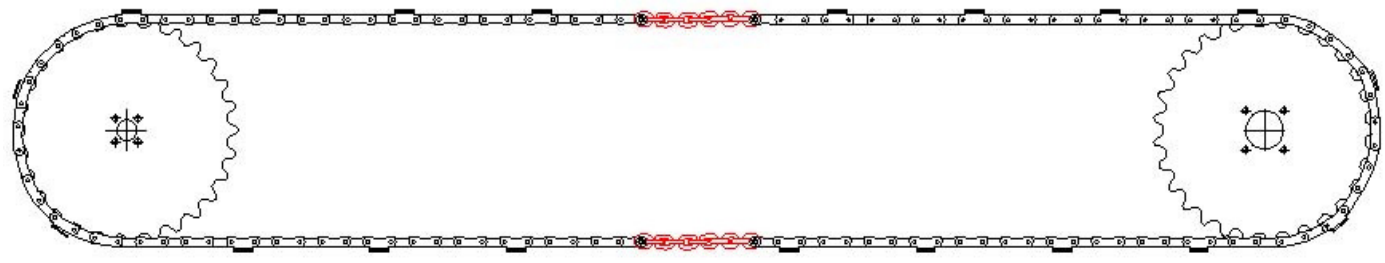

Fig. 2. Articulated chain with the stretches on opposite sides replaced by chains with closed rings

Each of the two aforesaid stretches is formed by a number $\mathrm{n}$ of links corresponding to an equal number of teeth $z_{n}$, on the wheels, which will be unmated during the passage of the stretch missing from links. In these conditions, the continuity of the transmission is ensured by the coupling of the teeth with the openings of the links adjacent to the missing ones; in this regard, indicating with $z_{a}$ the number of these "active" teeth, the following empirical formula could be useful:

$$
z_{a}>2 \cdot z_{n}
$$

This technical solution was created by the Pulcinelli Giovan Battista \& C Ltd Manufacturer, located in Anghiari (Arezzo province, Italy) and has been patented in Italy. It is a joint device that allows folding of an articulated roller chain in planes different from that of operation (Figure 3). A joint device of this type is useful, if it is needed to reduce the size of the transmission itself, in case it is not working $[19 ; 20]$.

\section{Tobacco leave harvester fitted with the articulated joint}

A type of machine frequently used in Italy for harvesting of Bright tobacco leaves essentially consists of a conveyor belt supported by a reticulated beam hinged at one end to a support frame, mounted behind the tractor. The conveyor belt consists of an articulated roller transmission chain, which links two toothed wheels having vertical axis. The driving gear wheel is mounted close to the support frame, whereas the other idler is placed at the other end of the mobile arm $[21 ; 22]$. The 
aforesaid chain supports the hooks, on which the tobacco leaves collected in the field are hanging [2325]. During the harvesting, the conveyor belt is arranged horizontally and transversely to the direction of advance of the tractor, a short distance from the apical leaf area of the vegetation $[26 ; 27]$. The tractor proceeds laterally outside the tobacco field and the operators collect the leaves and hang them on the hooks of the conveyor belt, so as to take them out of the field for the subsequent processing phases (Figure 4).

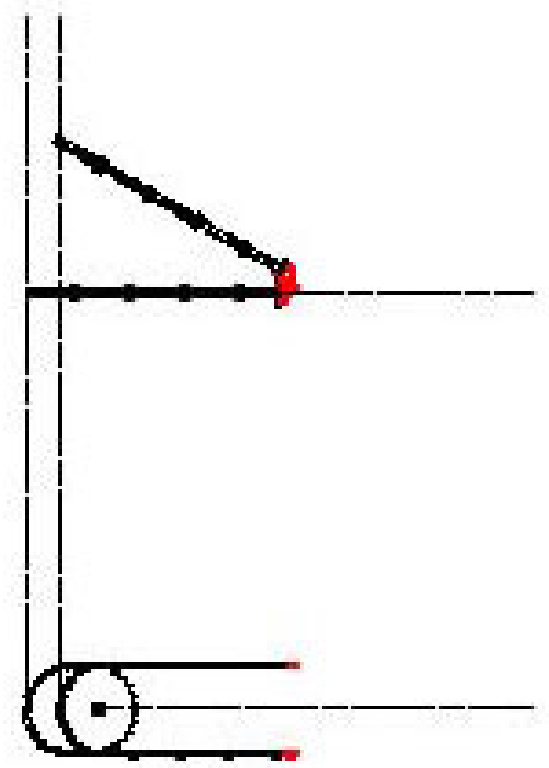

Fig. 3. Articulated chain fitted with folded stretches in a plane different from the operation one

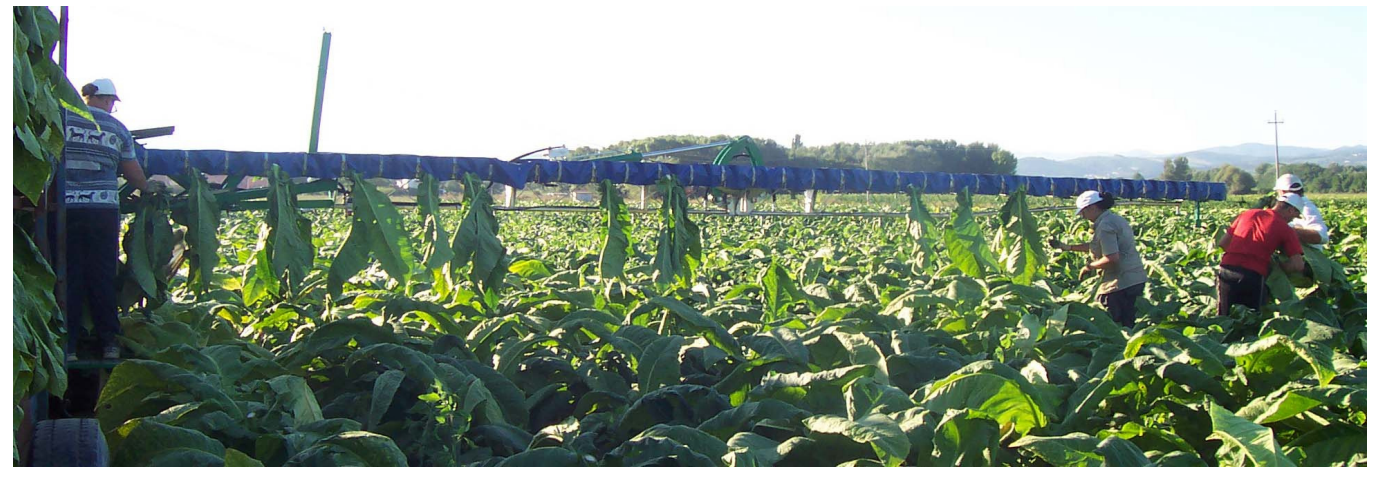

Fig. 4. Conveyor belt during harvesting of Bright tobacco leaves

In order to carry out road transfers, it is necessary to reduce the transversal dimensions of the machine, so to comply with the sizes provided for by the highway code. This reduction in size is very difficult due to the rigidity of the articulated chain, which does not allow for flexing of the links.

\section{Results and discussion}

The set up articulate joint

Figure 5 shows the articulated roller chain on which 5 consecutive links have been removed, in symmetrical positions with respect to the axis joining the centres of the wheels. The continuity on each stretch is obtained by connecting the ends of two ordinary chains to the loose links of the articulated chain. The two ring chains are connected, by means of pins, on the external sides of the disconnected links, so as to form a space compatible with the thickness of the wheels: this causes the teeth corresponding to the missing articulated chain section to fit between the two strips of ordinary chain, without hindering the motion of the wheels (Figure 6). The stretches of close ring chains allow, with the transmission stopped, to fold the articulated chain, so that a part of it can be overturned in a plane different from that of operation. 


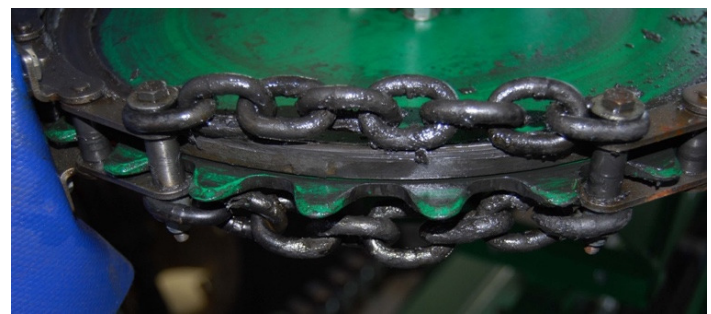

Fig. 5. Two ring chains linkedcomplying with the thickness of the wheel

\section{Tobacco leave harvester fitted with the articulated joint}

The black tobacco leave harvester, manufactured by Pulcinelli G.B. \& C Ltd, consists of a boxed steel support frame, which is linked to the rear 3 point attachment of a wheeled agricultural tractor ("fully mounted coupling") (Figure 6). The end of a steel truss beam, able to rotate in the horizontally plane, is anchored to the support frame by means of a hinge; whereas the other end is hinged, in turn, to the second beam, having the same mechanical and structural characteristics as the first. A hydraulically operated mechanism allows the two beams: 1) to be positioned horizontally on each other as an extension of a single movable arm; 2) to fold over each other.

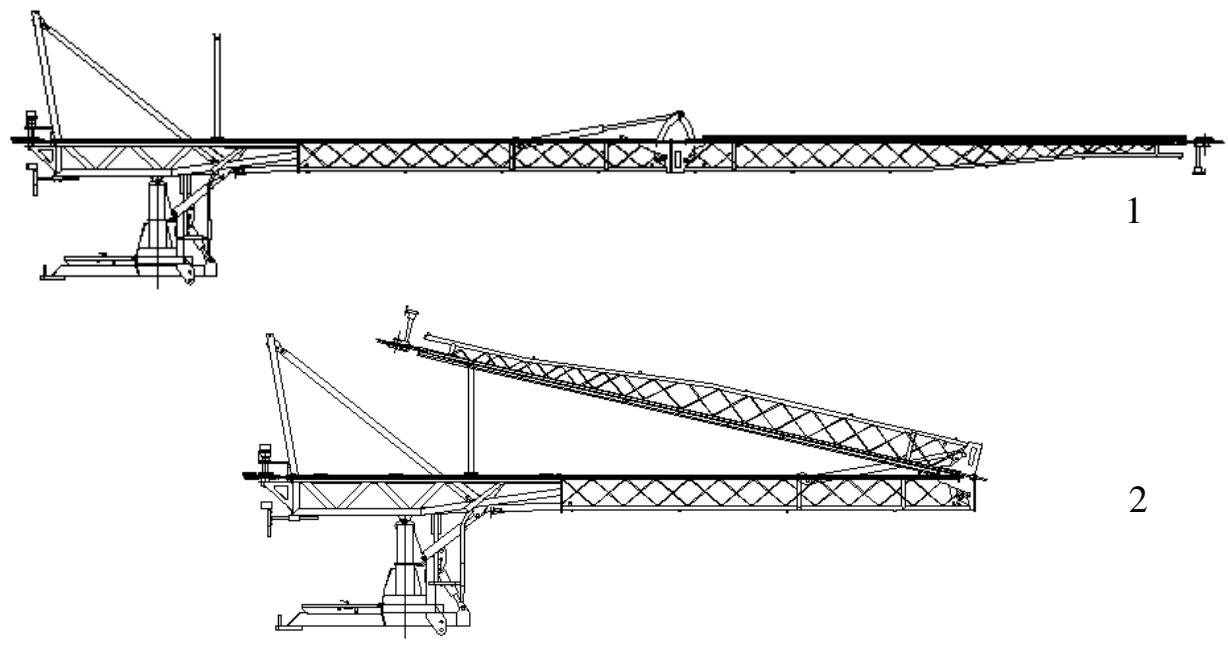

Fig. 6. Black tobacco leave harvester, manufactured by Pulcinelli G.B.\& C Ltd:

1 - beams positioned as a single movable arm; 2 - beams folded over each otherr

Figure 7a and Figure 7b show the labour-aid tobacco leave harvester fitted with the articulated joint mounted on a wheeled tractor. In particular, Figure 7a reports the tractor-and-implement arranged for the road transport, whereas the beams folded over each other can be seen in Figure $7 \mathrm{~b}$.

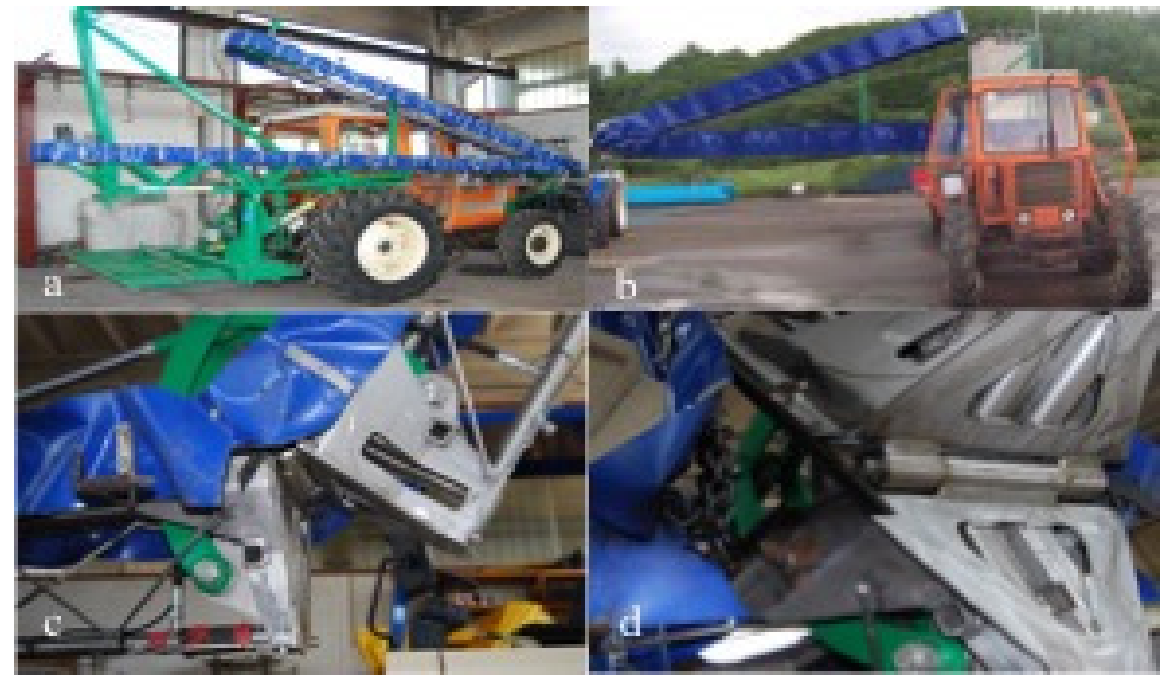

Fig. 7. Tobacco leave harvester 
The hinge for the arm folding is shown in Figures $7 \mathrm{c}$ and $7 \mathrm{~d}$. In detail, the chains with the closed rings is highlighted in Fig. 7d. This aggregate tractor-and-implement is currently used in a farm located in the surroundings of Città di Castello (Perugia province, Italy) in Virginia Bright tobacco cultivation. The performance of the machine is always very good and the articulated chain with the stretches replaced by chains with closed rings always works correctly and has never required maintenance.

\section{Conclusions}

An articulated joint has been created that can be mounted in articulated roller chains, making it possible for folding in planes different from the operative one.The good performance of the labour-aid machine for harvesting of tobacco leaves, in which thearticulated roller chains are fitted with the set up articulated joint, highlighted proper behavior of the aforesaid device. The articulated joint has been patented and can be used for articulated roller chains.

\section{Acknowledgements}

The authors equally contributed to the present study.

\section{References}

[1] Lodge C.J., Burgess S.C. An investigation into the selection of optimum chain and sprocket size. Journal of Engineering Design, Vol. 15 (6), 2004, pp. 563-580.

[2] Palle G., Bakrač L., Opančar A. A Walking roller chain. Emergent Scientist 2(6), 2018. DOI: 10.1051/emsci/2018005

[3] Bulgakov V., Pascuzzi S., Nadykto V., Ivanovs S. A mathematical model of the plane-parallel movement of an asymmetric machine-and-tractor aggregate. Agriculture (Switzerland), vol.8(10), 2018, 151.

[4] Ihsan Toktas, Hudayim Basak. Chain gear design using artificial neural networks. Computer Applications in Engineering Education 20 (1), 2012, pp. 38-44.

[5] Pascuzzi S., Cerruto E. An innovative pneumatic electrostatic sprayer useful for tendone vineyards. Journal of Agricutural Engineering, vol. 46(3):458, 2015, pp. 123-127.

[6] Kraszkieicz A., Kachel M., Parfiniuk S., Zając G., Niedziółka I., Sprawka M. Assessment of the possibility of using hemp biomass (Cannabis sativa L.) for energy purposes: a case study. Appl. Sci.-Basel 2019 Vol. 9 Iss. 20 4437, DOI: 10.3390/app9204437

[7] Spicer J.B. Effects of the Nonlinear Elastic Behavior of Bicycle Chain on Transmission Efficiency. Journal of Applied Mechanics, 80(2), 2014, pp 300-307. DOI: 10.1115/1.4007431

[8] Lodge, CJ and Burgess, SC.. A model of the tension and transmission efficiency of a bush roller chain. Proceedings of the Institution of Mechanical Engineers, Part C, 216, 2002, pp. 385-394.

[9] Kidd M. D., Loch N. E., and Reuben, R. L. Experimental Examination of Bicycle Chain Forces Experimental Mechanics, 39(4), 1999, pp. 278-283. DOI: 10.1007/BF02329805

[10] Blicharz-Kania, A., Pecyna, A., Krajewska, M., Andrejko, D., Szmigielski, M., Zawiślak, K., Sobczak, P., Berbec, A. Chemical properties of tobacco seed oil. Przemysł Chemiczny, 2018, vol. 97(11), 1906-1909, DOI: 10.15199/62.2018.11.18

[11] Sobczak, P., Mazur, J., Zawiślak, K., Panasiewicz, M., Żukiewicz-Sobczak, W., Królczyk, J., Lechowski, J., Evaluation of Dust Concentration During Grinding Grain in Sustainable Agriculture. Sustainability, 2019, vol. 11(17), 4572, DOI: 10.3390/su11174572

[12] Przywara A., Kachel M., Koszel M., Leszczyński N., Kraszkiewicz A., Anifantis A. S. The influence of digestate on the static strength of spring rapeseeds (Brassica napus var. arvensis). Sustainability, vol. 11(7), 2133, 2019.

[13] Kraszkiewicz A., Stryjecka M., Nowosad N., Kocira S. Obciążenie środowiska produktami spalania peletów z biomasy roślinnej w kotle górnego spalania. Rocz. Ochr. Śr. 2018 T. 20 s.1269-1285.

[14] Kachel M., Matwijczuk A., Sujak A., Czernel G., Niemczynowicz A., Nowicka A. The Influence of Copper and Silver Nanocolloids on the Quality of Pressed Spring Rapeseed Oil. Agronomy 2019, 9(10), pp. 643. 
[15] Przywara A. The impact of structural and operational parameters of the centrifugal disc spreader on the spatial distribution of fertilizer. Agriculture and Agricultural Science Procedia, vol. 7, 2015, pp. 215-222.

[16] Anifantis A.S., Camposeo S., Vivaldi G.A., Santoro F., Pascuzzi S. Comparison of UAV photogrammetry and 3D modeling techniques with other currently used methods for estimation of the tree row volume of a super-high-density olive orchard. Agriculture (Switzerland), vol. 9(11), 2019, 233.

[17]Russo G., Verdiani G., Anifantis A.S. Re-use of agricultural biomass for nurseries using proximity composting. Contemporary Engineering Sciences, vol. 9(24), 2016, pp. 1151-1182.

[18] Bulgakov V., Pascuzzi S., Santoro F., Anifantis A.S. Mathematical Model of the Plane-Parallel Movement of the Self-Propelled Root-Harvesting Machine. Sustainability Volume 10(10), 2018, 378 - DOI: $10.3390 / \mathrm{su} 10103614$

[19] Santoro F., Anifants A.S., Ruggiero G., Zavadskiy V., Pascuzzi S. Lightning Protection Systems Suitable for Stables: A Case Study. Agriculture Volume 9(4), 2019, 72 - DOI: 10.3390/agriculture9040072

[20]Żukiewicz-Sobczak W., Sobczak P., Rogóż A., Wojtyła-Buciora P., Kozak M., Zagórski J. Valuation of the content of selected elements in herbs cultivated in organic farms in the Lublin region. Proceedings Paper, Farm Machinery And Processes Management In Sustainable Agriculture, 2017, 461-464, DOI: 10.24326/fmpmsa.2017.83

[21]Rusinek-Prystupa E., Lechowski J., Żukiewicz-Sobczak W., Sobczak P., Zawiślak K. Influence of Citrosept addition to drinking water and Scutellaria baicalensis root extract on the content of selected mineral elements in blood plasma of turkey hens. Annals Of Agricultural And Environmental Medicine. 2014, Vol. 21(3), 595-600, DOI: 10.5604/12321966.1120609

[22] Sujak A., Muszyński S., Kachel-Jakubowska M. Quality of rapeseed bio-fuel waste: optical properties. Int. Agrophys. 2014, 28(2): 213-218DOI: https://doi.org/10.2478/intag-2014-0010

[23] Anifantis A.S., Pascuzzi S., Scarascia Mugnozza G. Geothermal source heat pump performance for a greenhouse heating system: An experimental study. Journal of Agricultural Engineering, vol. 47(3), 2016, pp.164-170.

[24]Bulgakov V., Pascuzzi S., Beloev H., Ivanovs S. Theoretical investigations of the headland turning agility of a trailed asymmetric implement-and-tractor aggregate. - Agriculture, 9(10), 2019, 224.

[25] Bulgakov V., Pascuzzi S., Adamchuk V., Kuvachov V., Nozdrovicky L. Theoretical study of transverse offsets of wide span tractor working implements and their influence on damage to row crops. Agriculture 9, 2019, 144

[26] Pascuzzi S., Santoro F. Analysis of the almond harvesting and hulling mechanization process: A case study. Agriculture 7(12), 2017, 100.

[27]Bulgakov V., Pascuzzi S., Ivanovs S., Kaletnik G., Yanovich V. Angular oscillation model to predict the performance of a vibratory ball mill for the fine grinding of grain. Biosyst. Eng. 171, 2018, 155-164. 